\title{
Narrativas transmediáticas en entornos digitales: la novela hipermedia Inanimate Alice y sus aplicaciones docentes
}

\author{
Ana ABRIL HERNÁNDEZ*1 \\ ana.ab.her@gmail.com
}

(Abstracts y palabras clave al final del artículo)

Enviado: 20 de abril de 2013

Evaluado: 26 de junio de 2013

Aceptado: 13 de julio de 2013

\section{INTRODUCCIÓN}

Debido a su popularidad, algunos libros clásicos se han adaptado desde hace décadas de la impresión a otros medios. Uno debe acercarse a toda adaptación con cierto cuidado, sabiendo que el original es algo completamente distinto a sus interpretaciones ecfrásticas. Una obra artística puede ser evocada en diversos medios, visuales (escultura, pintura) o acústicos (música) por ejemplo, además de plasmada en distintos géneros (poesía, teatro, novela, etc.). La misma temática puede ser abordada de distintas maneras a través de diversos géneros y estilos narrativos, frecuentemente vinculados, como diría Mikhail Bakhtin en su formulación sobre el cronotopo, al formato material o medio de comunicación a través del que pasa el acto de narración. Frecuentemente, la correlación de ideas y palabras presenta además una respuesta estética asociada, sentimiento que puede ser expresado y trasladado a otros géneros y formatos.

Las siguientes líneas presentan el caso de una novela digital basada en la conocida historia de Lewis Carroll, Alicia en el país de las maravillas (1865). Es importante señalar que Inanimate Alice <http://www.inanimatealice.com/ $>$ no es simplemente una novela. El formato digital permite la combinación de distintas modalidades multimedia. La narración de Inanimate Alice, creada por la escritora canadiense Kate Pullinger y el artista digital Chris Joseph, es una de las obras pioneras en el desarrollo de la alfabetización digital en colegios e institutos de todo el mundo. Se inspira en la conocida obra de Carroll de una manera superficial. En el original se presenta un mundo onírico donde los personajes inanimados tienen poder sobre los animados, como por ejemplo la Reina de Corazones. La novela digital Inanimate Alice refleja esta dimensión inanimada en el personaje digital de la protagonista y en los numerosos aparatos electrónicos que la rodean. Esta dimensión digital inanimada

\footnotetext{
* Colaboradora Honorífica del Dpto. de Filología Inglesa II (Literatura de los Países de Lengua Inglesa) de la Facultad de Filología de la UCM.
} 
tiene especial importancia ya que es la que guía y ayuda a Alice en muchas situaciones a lo largo de la serie. Además, la transposición intermedial (adaptación) de un medio a otro ha ampliado las posibilidades de representación gracias al amplio abanico de mecanismos multimodales (Grishakova y Ryan, 2010:3) y a la base narratológica como tertium comparationis transmediático (Wolf, 2003, 2005, 2011). Wolf emplea el término "transmedialidad" para aludir a fenómenos cuya representación no está ligada a un medio determinado, como es el caso de la narrativa. "Internal transposition" se refiere a las adaptaciones de un medio a otro e "intermedial reference" a los textos dedicados exclusivamente a profundizar en otros medios, como sería el caso de una novela de carácter biográfico.

Como otras obras digitales, Inanimate Alice está pensada para combinar los diversos elementos del relato siguiendo una estructura hipertextual. El hipertexto lo componen patrones tanto cronológicos y teleológicos -generalmente empleados en la narrativa impresa- como recursivos y auto-reflexivos, que se multiplican mediante la replicación y la repetición. Las narrativas nucleares complejas aumentan la incertidumbre y el suspense, puesto que, como indicaba Peter Brooks (1992), la mayoría de los lectores prefieren leer una trama definida que siga sus expectativas en lugar de enfrentarse a una estructura abierta. Sin embargo, la ambigüedad funciona también para implicar al lector en la resolución de conflictos o problemas presentados en el relato. En el caso de las estructuras hipertextuales, la elección de distintos itinerarios posibles permite que el lector se convierta en un lector más activo; no solo porque puede elegir su recorrido de lectura, sino también porque muchos textos digitales permiten en menor o mayor medida la manipulación de sus estructuras nucleares mediante intervenciones a través del teclado, el ratón, el micrófono, o la cámara (un ejemplo de texto manipulable mediante la incorporación de la imagen de la cámara Web se presenta en Bouchardon y López-Varela, 2011). Mientras que los medios analógicos convencionales implicaban un ensamblaje manual de los elementos visuales/verbales en una composición o secuencia, el medio digital puede generar varias versiones y variantes que a menudo se consiguen de forma automática, simplemente por la estructura modular de las unidades de información digital (Manovich, 2002: 36).

La novela digital que presenta este artículo, Inanimate Alice, se dirige a un público juvenil convirtiéndose en un híbrido entre novela y juego interactivo, y está formada por una serie de episodios que narran las aventuras de Alice mientras viaja por todo el mundo con sus padres. Antes de que se estrenara el primer episodio en 2005, Pullinger y Joseph habían diseñado ya otra novela digital, junto a Stefan Schemat: The Breathing Wall (2004) ( $<$ www.thebreathingwall.com $>$ ) que, a diferencia de Inanimate Alice, requiere una respuesta realmente activa por parte de un lector-participante.

El desarrollo de las tecnologías online ha tenido un impacto importante en el ámbito educativo desde los primeros momentos de su popularización en la década de los noventa. Numerosos proyectos pedagógicos empleaban el ordenador en función de los ejes de aprendizaje perfilados por Benjamin Bloom (1971), el afectivo, el cognoscitivo y el psicomotor (para un resumen de algunos de los proyectos de este tipo, López-Varela, 2006). Cada uno de los dominios registraba una serie de sub-procesos basados en recepción y respuesta a estímulos informativos, además de valoración y organización de las ideas adquiridas, y su posterior interiorización a través de 
los mecanismos de memoria. Desde el punto de vista semiótico, la importancia de los aspectos espacio-temporales queda de manifiesto en la distinción entre descripción y narración. En el primero, se capta la atención hacia un momento perceptivo concreto (el término 'punto de vista' funciona aquí como una estructura metonímica y metafórica que se refiere no solo a la visualidad sino a cualquier otro sentido -oído, olfato, gusto, tacto) a través de estructuras deícticas. En la estructura temporal de la narración, la temporalidad abstracta se concreta en la metáfora espacial del desplazamiento, que aporta nuevas panorámicas o puntos de vista. La intrincada red de relaciones y asociaciones internalizan lo narrado mediante la experiencia estética, es decir, la internalización de la sensación (López-Varela, 2013).

En las composiciones digitales, textos e imágenes, fijas o en movimiento en el formato vídeo, compiten por la atención del lector junto con información que llega por medio del formato auditivo (música, ruido, etc.). En los textos impresos, la mirada y el tacto del lector al pasar la página facilitan el avance de la narración. Los formatos digitales se orientan cada vez más hacia los aspectos táctiles (teclado, ratón, pantallas sensibles al tacto), e incorpora cada vez más las imágenes que el formato impreso no permitía a causa de su elevado coste. Por su mayor facilidad de procesamiento cognitivo, ya que refleja la realidad mediante similitud o analogía, la imagen es con frecuencia el signo que la mente decodifica con mayor facilidad. De ahí que en los formatos digitales la imagen adquiera cada vez más una importancia clave para captar la atención. Este artículo ofrece una aproximación al funcionamiento de la interacción texto/imagen en la novela interactiva Inanimate Alice, con el fin de adentrarnos en las claves semióticas que la convierten en un referente educativo mundial y de analizar la carga interactiva real de la obra.

\section{LOS MODOS VISUAL Y ESCRITO EN TÉRMINOS DE INTERACCIÓN MULTIMODAL}

Una de las primeras teorías en abordar las interacciones texto-contexto fue la lingüística sistémico-funcional (SFL), desarrollada por Michael Halliday (1985) profesor de lingüística de la Universidad de Sidney en Australia. La SFL se basa a su vez en la teoría de estructuras sistémicas de Raymond Firth $(1925,1936)$, quien desarrolló los conceptos de contexto de la situación y contexto de la cultura a partir de Bronislaw Malinowski $(1944,1945)$. La SFL se interesa por las realizaciones funcionales semióticas en estructuras concretas que operan en distintos niveles y dimensiones en torno al lenguaje. Dentro de los procesos que tienen lugar en la comunicación, la SFL distingue entre procesos de relaciones, procesos materiales, procesos verbales, procesos existenciales y finalmente procesos de comportamiento. Los procesos de relaciones presentan enunciaciones y se subdividen en identificativos y atributivos. Se habla de que X (denominado 'token') sirve para definir la identidad de Y (value). Halliday (1985: 115) señala que el 'token' es el signo mientras que 'value' o valor es lo que confiere significado referencial y funcional al signo. En las relaciones atributivas se asigna una cualidad, clasificación o descripción (atributo) al participante (carrier), que suele realizarse mediante un nombre o grupo nominal. 
Aunque las teorías de Halliday no incorporan estudios que combinen texto e imagen, comprobaremos su efectividad en el análisis del primer episodio de Inanimate Alice. Sin llegar a analizar los complejos procesos de coherencia en la novela digital, el análisis sistémico-funcional que desarrollaremos se verá complementado con la idea de Marina Grishakova (2004), de la escuela de semiótica de Tartu, quien distingue entre procesos metaverbales y metavisuales (el prefijo 'meta' viene del griego y tiene un sentido análogo al carrier de Halliday). Partiendo del trabajo de Yuri Lotman, Grishakova señala que la equivalencia entre unidades lingüísticas discretas y las entidades semánticas continuas es aproximada, lo que hace que los lenguajes visual y verbal no puedan traducirse entre sí de manera absoluta (Grishakova, 2013: 313). Potencialmente, escribe la autora, cualquier texto verbal o visual es un "imagetext" o "iconotext" donde los signos icónicos o los simbólicos predominan, y donde ambos tipos de signos se encuentran en un estado de mayor o menor tensión mutua y explícita (Grishakova, 2013: 314) dentro del cual se complementan: "The metaverbal text (e.g. an ekphrastic text, cine-novel, or graphic poetry) reflects on the incomplete nature of verbal medium by probing the limits of verbal representation and appealing to the visual forms (graphic elements, real or virtual film shots, works of art, dreams, hallucinations, mental imagery, etc.) [...] The metavisual text reflects on the incomplete nature of visual representation by juxtaposing image with verbal message and revealing their discrepancy." (315).

La primera imagen del primer episodio de la obra que aquí se analiza muestra un fondo negro con unas pequeñas letras blancas en mitad de la pantalla. La frase que abre el relato, "My name is Alice", muestra el proceso de identificación del personaje en el que encontramos el token ("My name"), un verbo de proceso no acentuado ("is") y el value, que es "Alice". La segunda frase, "I'm 8 years old", señala un proceso atributivo donde el carrier ("I") se relaciona con su atributo ("8 years old") mediante un verbo de proceso no acentuado ("am"). Estos procesos operan de manera simultánea a nivel de las imágenes en los distintos episodios de la novela digital. En la escena 13, por ejemplo, leemos: "The jeep has giant wheels, and a big satellite transmitter on the roof [...]", donde el participante (en términos semánticos) es el jeep. Este es otro caso de proceso de relación sin un vector real; es decir, sin una línea imaginaria que estaría presente en el modo visual y que serviría para relacionar el elemento aludido con el participante (Alice) que lo está observando. Este proceso consta de un carrier inanimado, un verbo de relación atributivo ("has") y un atributo. La imagen es un elemento imprescindible porque ayuda a visualizar la información que se comunica en el modo lingüístico.

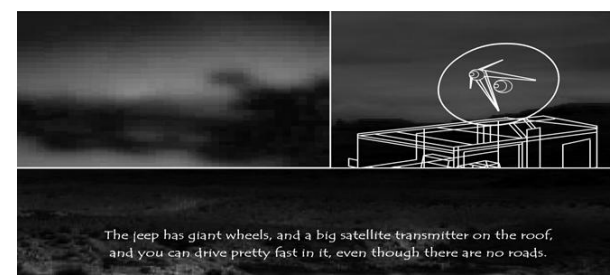

Figura 1. Escena 13 del primer episodio donde se combina texto con imágenes. 
Las imágenes tienen un papel fundamental en la textualidad digital. Aquí, lo metaverbal, un atributo de los textos verbales que evoca las imágenes, y lo metavisual, un atributo de las imágenes que se refleja en la naturaleza incompleta de las representaciones visuales, como señalábamos antes, se complementan. Descripción y narración se alternan para capturar la atención.

Si bien la textualidad digital en Inanimate Alice no incluye elementos cinéticos (en "Digital Textuality and its Behaviors" Leonardo Flores enumera las operaciones textuales características de los textos digitales; entre ellas se encuentran elementos cinéticos derivados de la ejecución de los códigos y los programas), sí contiene aspectos "de respuesta" y mecanismos "auditivos" que se mueven en la pantalla a intervalos de lectura regulares. Para ilustrar este diálogo entre modalidades, presentamos la escena 16 (figura 2 de abajo) donde leemos: "then I mail the photos to my Dad so he will know that we are on our way, even if he doesn't answer". En este caso, se ve la imagen de la videoconsola de Alice y la acción de enviar las fotos se convierte en el proceso principal de la oración, en la que el sujeto pasivo o affected ("the photos"), el sujeto activo o agent ("I") junto al verbo material en presente ("mail") aparecen también parcialmente en el modo visual (el agente no aparece). Al no existir un agente en el modo visual no aparecen vectores que lo relacionen con el sujeto pasivo (affected) y, por tanto, la estructura narratológica solo está presente en el modo de la palabra escrita:

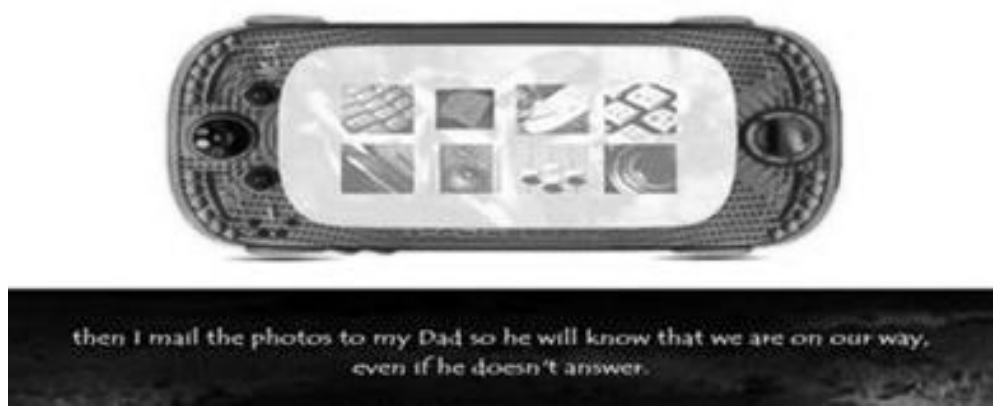

Figura 2. Escena 16 del primer episodio donde es el modo escrito el que sirve de hilo para la nararción en contraposición al modo visual.

Muchos procesos comunicativos presentes en el primer episodio se expresan lingüísticamente en presente simple, como es el caso de "We drive for a long time" (escena 17). Este constituye otra acción en la que no podemos ver el acto de conducir el coche, sino únicamente el resultado de dicha acción (es decir, la carretera frente al vehículo). De ahí que no existan vectores presentes en el modo visual ni tampoco sujeto activo (agente), si bien sí que hay un sujeto pasivo (affected) implícito en el modo lingüístico (el coche que está conduciendo).

Tales ejemplos de procesos materiales son relevantes a la hora de analizar el grado de empatía que cabe esperar del usuario de la novela. En ninguno de ellos se muestra al agente en el modo visual. Por tanto, la falta de una imagen visual del narrador de la historia nos hace suponer que debería explotarse más el uso de las 
posibilidades de los dos modos principales que utiliza esta obra digital. Si la novela mostrara un uso más exhaustivo de los modos visual y lingüístico, el significado potencial de cada ejemplo sería más evidente para el usuario, y éste tendría más facilidad para interactuar empáticamente con la historia en mayor profundidad.

La categoría de procesos más numerosa en la obra es la de los procesos mentales, debido a que la protagonista nos informa continuamente de lo que ve, siente y piensa. Un ejemplo que ilustra este tipo de procesos es la escena 31, en la que la narradora afirma: "And we see my Dad". Aquí se describe un proceso mental perceptivo donde, de nuevo, no se muestra ni al ser que lo experimenta (experiencer) (Alice) ni el fenómeno en el modo visual. Esto es así porque lo que se muestra en la imagen es solo un fondo de tierra marrón que simboliza el lugar del encuentro. Nos situamos en un caso donde el modo principal es el visual, y el modo escrito acompaña a la imagen (por ejemplo en la escena 28 , figura 3 ) aquí, detrás del texto "So I look out of the window, though there is nothing to see" aparece el marco de una ventana y un paisaje en su interior. Se trata de un proceso mental-perceptivo sin ningún experiencer en el modo visual; por tanto, tampoco hay vectores, solo el fenómeno (el exterior a través de la ventana). El recurso del encuadre (framing) se analizará en la sección siguiente como elemento clave en la composición de imágenes.

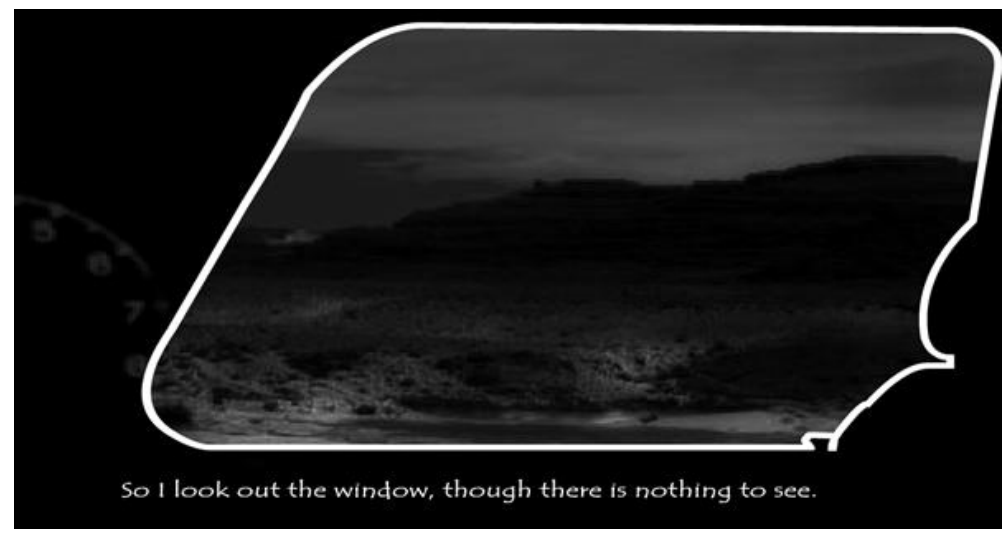

Figura 3. Escena 28 del primer episodio donde tampoco hay un narrador visible en las imágenes.

\section{EL USUARIO COMO INTÉRPRETE Y LA COMPOSICIÓN FRAGMEN- TARIA DE LAS IMÁGENES}

En este estudio se ha analizado la falta de agentes activos en el modo de las imágenes de la novela digital Inanimate Alice, tomando como muestra el primer episodio. Se ha demostrado que esta falta conduce a una reducida interrelación entre las imágenes y el lector-participante, ya que estas son el único elemento visual con el que se establece comunicación. Debido a la carencia de sujetos activos que se reflejen en las imágenes, la obra no emplea el recurso de la vista, lo cual disminuye el nivel de acercamiento empático con la protagonista. Se hace más difícil determinar 
el grado de distancia intersubjetiva que existe entre Alice y el lector-participante. Esta sección utilizará como base el primer capítulo de esta obra digital para estudiar el rol del usuario dentro de la novela y cómo éste se relaciona con la historia.

En general, el tamaño de los marcos es de media distancia a larga distancia, hecho que no facilita el acercamiento de los acontecimientos que se narran, ni permiten conectar de forma más estrecha con la protagonista. Además los actos de habla que predominan son en su mayoría declarativos, acompañando la sensación general de fragmentación narrativa que se ve realzada por las imágenes, puesto que las afirmaciones declarativas no requieren de un oyente (en este caso, usuario de la novela) que genere una respuesta o al que se le pida que se involucre activamente en la historia.

En cuanto a la interrelación entre los componentes de las imágenes, como se ha explicado más arriba, la gran mayoría de las imágenes contienen algún tipo de mecanismo pictórico de encuadre con el fin de alcanzar un equilibrio entre los elementos inconexos que las componen. El recurso semiótico más frecuente para separar los elementos que componen una obra son las líneas de encuadre. Esas líneas se encuentran no solo para separar el objeto del que se está hablando del espacio en el que se encuentra, sino también para separar ambos del modo lingüístico.

Otro recurso semiótico que aparece en la novela y que se emplea para dividir las imágenes son las líneas o espacios en blanco que separan el espacio del texto del espacio de la imagen, si bien manteniendo la sincronía de color, como en la escena 18:

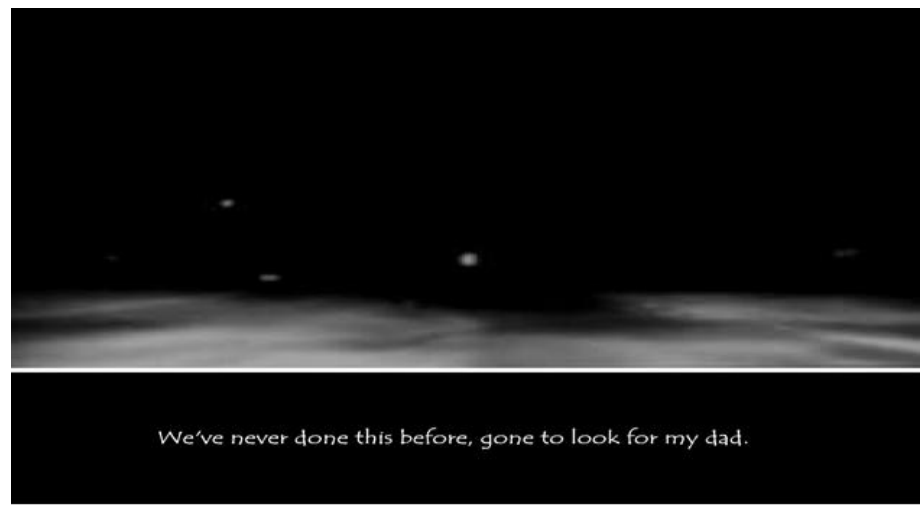

Figura 4. Escena 18 del primer epsiodio donde los dos modos principales quedan claramente delimitados y separados.

En otros casos, no existen fronteras definidas que desconecten la imagen del texto, entonces los colores funcionan como recurso semiótico para distinguirlos cuando se muestran letras blancas sobre un fondo de color negro. La escena 26 ilustra este hecho: 


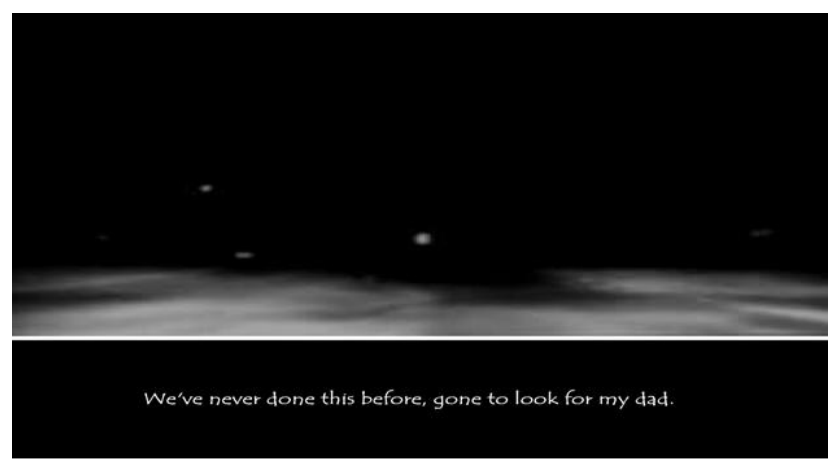

Figura 5. Escena 26 del primer episodio donde el modo escrito (texto) solapa al visual (imagen de fondo).

Existen otros recursos más complejos de encuadre y focalización. Por ejemplo, en las representaciones icónicas de objetos, son estos los que actúan como encuadre puesto que contienen el modo escrito en su interior. La escena 19 es un buen ejemplo de esta división. En ella, la consola de Alice (en forma de representación icónica) aporta el marco para el modo lingüístico; podemos apreciar dicho caso en la figura 6 de abajo:

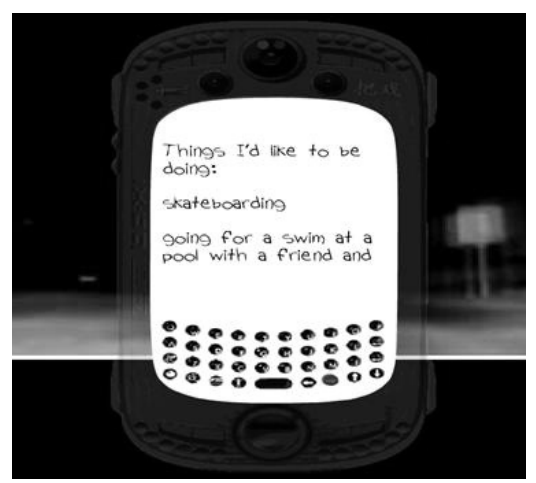

Figura 6. Escena 19 del primer episodio donde el modo visual actúa como marco (consola) para el texto.

Desde la perspectiva de Bloom sobre los elementos psicomotrices que incidirían en la recepción afectivo-cognitiva potenciados por la interacción online, es interesante analizar aquellos relativos a la percepción visual. Cada usuario se centrará o percibirá primero un cierto elemento, en función de sus capacidades biológicas y sus preferencias. El tono oscuro que predomina en la novela, en ocasiones tintado de imágenes de color, funciona como un elemento perceptivo-cognitivo fundamental. La llamativa consola rosa destaca sobre todo si aparece situada sobre un fondo blanco: 

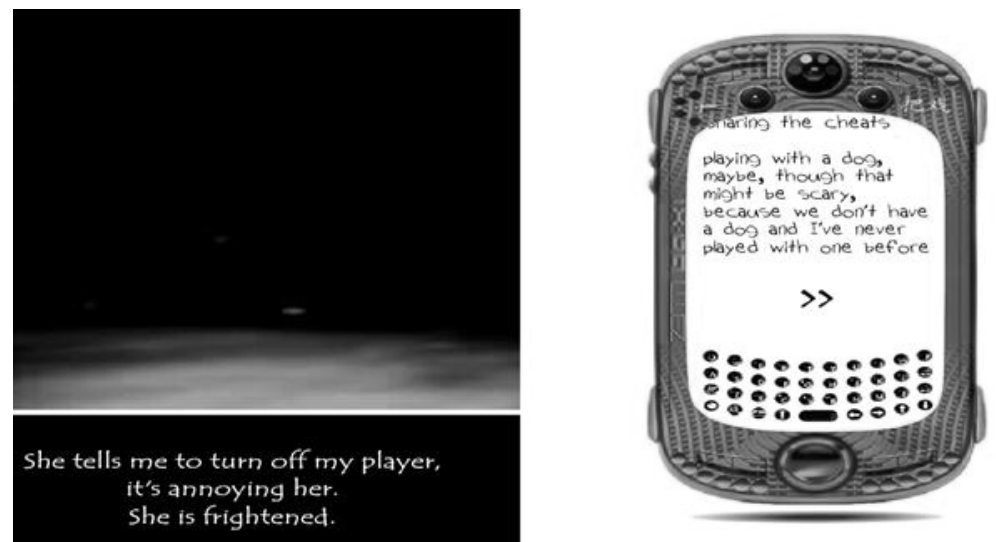

Figura 7. La consola rosa destaca visiblemente sobre el fondo blanco, en especial si se coloca junto a una imagen de fondo oscuro.

En realidad, a lo largo de los sucesivos episodios de la historia se puede ver cómo el modo lingüístico recibe claramente más importancia que las imágenes. Otra prueba de ello es el hecho de que los textos se muestren superpuestos a las imágenes y no fuera de ellas. Frank Nack lo denominaría "narranotation", es decir, anotaciones a las imágenes. En Inanimate Alice se emplean fundamentalmente para dar información sobre los espacios urbanos y las localizaciones geográficas. La figura 8 que se muestra más abajo representa un ejemplo de "narranotation":

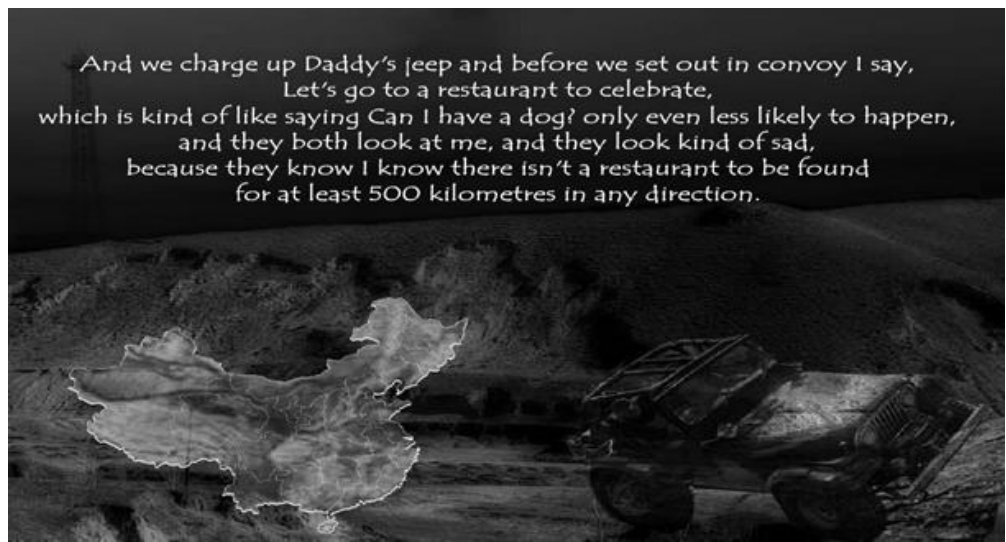

Figura 8. Narranotation en el modo visual bajo el texto que la describe.

Los elementos deícticos de contacto, sobre todo de contacto visual, son también fundamentales. La importancia de la presencia física de la figura humana en los procesos de comunicación es especialmente importante a la hora de establecer un contacto afectivo (López-Varela, 2011). La línea o vector invisible que se dibuja entre el personaje de la obra y el lector-usuario intensifica la cercanía entre ambos. Dicha importan- 
cia radica en la necesidad de establecer una comunicación visual negociada entre los interlocutores (digital y real) como base del intercambio comunicativo. Este contacto visual es, si cabe, más importante en el aprendizaje infantil a edades tempranas, donde los gestos cobran más relevancia que el lenguaje verbal. Por ello, la ausencia de la figura del interlocutor digital en Inanimate Alice resulta llamativa e incomprensible.

Aunque la novela no muestra ninguna figura humana como tal, sí contiene dibujos de la misma. Por ejemplo el personaje de Brad, que parece ser una especie de extensión de la identidad de Alice (a veces incluso de su mente). En ocasiones, Brad aconseja a Alice lo que debe hacer, como si fuese una forma de conciencia parecida al personaje de Pepito Grillo en la historia de Pinocho. Cada vez que Brad aparece en pantalla atrapa la atención del lector-participante porque es prácticamente la única figura humana en casi toda la historia. En la imagen que se muestra a continuación, el texto en blanco pierde relevancia frente a la imagen de Brad, ambos en fuerte contraste sobre el fondo oscuro.

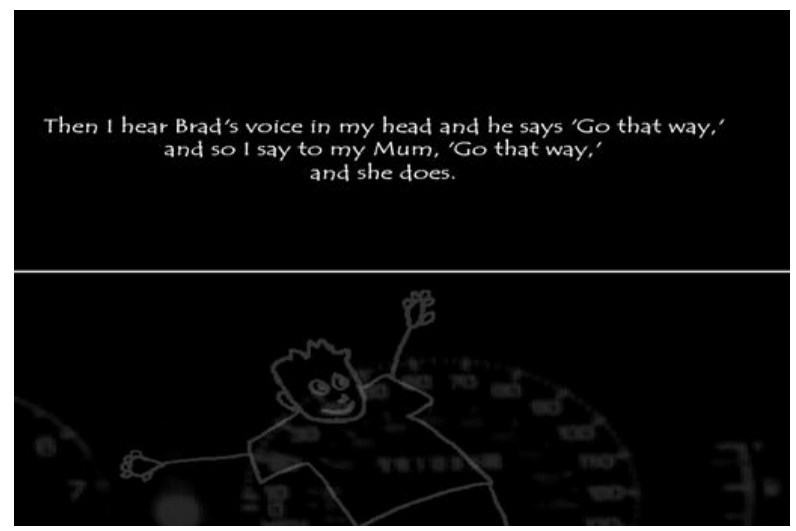

Figura 9. La imagen de Brad como única figura humana capta la atención del niño antes que las letras de la pantalla.

En la mayoría de las novelas en formato impreso, el escenario en el que transcurren los acontecimientos que se narran se plasma en la obra a través del uso de adjetivos, figuras retoricas, etcétera. Cuando se trata de los textos digitales y multimodales, el tema del escenario adquiere mayor importancia. En el caso concreto de Inanimate Alice, el usuario se encuentra con una atmósfera oscura, tensa y tenebrosa, cuyos elementos perceptivos incrementan la relevancia del modo lingüístico de las letras blancas.

\section{VISIÓN GENERAL APLICADA DEL USO DE ESTA NOVELA-JUEGO EN LA EDUCACIÓN}

Inanimate Alice es un híbrido entre novela educativa y juego que se emplea como material pedagógico en la Educación Primaria y Secundaria en muchos países del mundo con el fin de potenciar la alfabetización digital (e-literacy o digital literacy). El interés por esta nueva disciplina ha hecho que se preste especial atención 
a las necesidades de los jóvenes y sus técnicas de aprendizaje. El acercamiento práctico e interactivo hacia cualquier asignatura del currículo de Primaria y Secundaria es fundamental para el aprendizaje en los tres ejes psicológicos mencionados por Bloom, el afectivo, el cognoscitivo y el psicomotor. La gran innovación que ha introducido el uso generalizado de Internet es la facilidad para incluir al lector-usuario en el mensaje que se desea transmitir. En este sentido, la novela hipermedia Inanimate Alice debería explotar más en profundidad la capacidad de involucrar al lector-participante en la obra e incrementar las aportaciones por parte de este. Una forma de conseguirlo sería incluir más figuras humanas o representar al sujeto hablante del modo escrito también en las imágenes y así aumentar la carga interactiva de la novela.

Esta novela cuenta con unas actividades a las que pueden acceder los educadores y que se encuentran fuera de los respectivos episodios. Si estos ejercicios para los alumnos se introdujesen en los episodios, por ejemplo, se ayudaría a desarrollar las habilidades digitales del niño-usuario al aparecer estas tareas en el contexto de la obra a la que se refieren. Esto está estrechamente relacionado con el modelo de input-process-outcome (aportación-proceso-resultado, mi traducción) descrito por Garris, Ahlers y Driskell (2002). Según este modelo, el primer paso en el uso del cualquier tipo de material docente es la presentación a los estudiantes tanto de las instrucciones como de las características de la obra en sí (o la herramienta que se vaya a utilizar) con el fin de destacar las propiedades más llamativas para el usuario.

Algunos autores (Fitch, 1997) han hecho especial hincapié en los aspectos positivos de la educación mediada por ordenador. Sin embargo, uno de los aspectos ausentes en los entornos digitales es el contacto visual (Fitch, 1997: 438). La ausencia de la figura física del educador o guía en el proceso de aprendizaje se asemeja a la falta de referencias humanas reales con las que el lector-participante pueda sentirse identificado. La carencia de una figura humana en la que el joven participante pueda auto-proyectarse obstaculiza el desarrollo de los ejes afectivo y cognoscitivo identificados por Benjamin Bloom. Esto, a su vez, impide que el usuario desarrolle un sentido de metaconciencia (ser consciente de la existencia de su propia consciencia) que permite un mejor aprendizaje. De nuevo, esta falta forma parte de los mecanismos interactivos que esta novela no desarrolla completamente y resulta en una pérdida de la unión entre el joven lector-participante de la novela y la protagonista de la historia.

Un elemento que dota de unidad estructural a la narrativa hipermedia que aquí se analiza viene de la propiedad de auto-reflexión que tiene el texto y que está presente en el episodio tres. En este episodio se alude directamente a la función pedagógica de la obra, cuando Alice afirma: "Ya sé que es triste querer ir a la escuela, pero nunca en mi vida he ido a la escuela y es algo que me gustaría probar, aunque la mayoría de los niños lo odien". De esta forma el lector-participante sí que establece una relación más próxima a la de la protagonista porque se emplea la carga metafictiva de estas palabras para conseguir una auto-identificación con el personaje de la obra.

Otro aspecto deficiente en esta obra hipermedia es el hecho de que las experiencias que se presentan son considerablemente simples y siguen patrones relativamen- 
te conservadores en su forma. Esto se percibe desde el momento en que la historia se desarrolla siguiendo una línea que lleva de una pantalla a la siguiente sin ninguna posibilidad de desviarse de la linealidad que la conforma. Como consecuencia, el lectorparticipante sigue una estructura narratológica tradicional, sin emplear, por ejemplo, las posibilidades que ofrecen los enlaces hipertextuales para desarrollar los procesos de búsqueda activa de información (López-Varela, 2006). Por ello, el patrón narrativo lineal que predomina en Inanimate Alice no ayuda al desarrollo de los mecanismos cognitivos de la mente humana que conectarían conceptos e ideas en forma de imágenes, es decir, los aspectos metaverbales y metavisuales antes descritos.

\section{CONCLUSIÓN}

Muchos estudios recientes profundizan en los beneficios de los juegos de ordenador con fines pedagógicos (sobre los juegos basados en las obras de Shakespeare, por ejemplo, Patrunjel, 2013). Muchos de estos beneficios se apoyan no solo en el formato hipertextual, que permite una mayor capacidad de iniciativa en la toma de decisiones lectoras, sino también en el diálogo semiótico intermedial, que permite la interacción de diversas modalidades perceptivas, ayudando a una mayor inmersión afectiva y cognitiva.

Este artículo ha ofrecido una aproximación semiótica al estudio de la interacción texto/imagen en una de las novelas digitales empleadas como modelo docente pionero en el desarrollo de competencias digitales. Algunas de las conclusiones que se han podido extraer de este análisis semiótico son las siguientes:

1. Este estudio de Inanimate Alice muestra cómo la novela digital manifiesta un estilo visiblemente conservador a nivel de interacción lector-participante. Los ejemplos han mostrado la escasa relación entre la información que se transmite en el medio escrito y en el medio visual (como la falta de representación visual del agent en las imágenes), empobreciendo como resultado el potencial afectivo-cognitivo de la novela. Además, su componente educativo se ve mermado por la ausencia de actividades prácticas a modo de ejercicios dentro de los propios episodios.

2. La primacía del modo escrito a lo largo de la novela solo se ve equilibrado por unas escasas escenas en las que se muestran figuras humanas como la de Brad. No obstante, la línea narrativa de la novela queda ampliamente plasmada en los textos de cada pantalla, por lo que no existe un equilibrio real entre los dos modos principales que se emplean.

3. La novela digital Inanimate Alice carece de una visión alternativa a la de la protagonista. La ausencia visual de este personaje en el relato y la falta de recursos hipertextuales realmente interactivos que permitan itinerarios múltiples reducen el componente interactivo e intersubjetivo de la obra, haciendo que su uso en las aulas sea, en mi opinión, limitado. Necesitaría una serie de revisiones con el fin de convertirla en una herramienta de educación online realmente efectiva. 


\section{REFERENCIAS BIBLIOGRÁFICAS}

Bakhtin, Mikhail (2004 / 1981): The Dialogic Imagination. Austin: University of Texas Press.

Bloom, Benjamin (1971): Taxonomía de los objetivos de la educación: la clasificación de las metas educacionales: manuales I y II. Trad. Marcelo Pérez Rivas. Buenos Aires: Centro Regional de Ayuda Técnica, Agencia para el desarrollo Internacional.

Bouchardon, Serge y López-VArela, Asunción (2011): "Making Sense of the Digital as Embodied Experience". En Material Aesthetics, Media Formats and Cultural Studies. (eds.) Tötösy, S.; López-Varela, A.; Sassy, H.; Miszkowski, J.Monographic issue. CLCWeb: Comparative Literature and culture 13.3 Purdue University Press

Brooks, Peter (1992 / 1984): Reading for the Plot. Cambridge: Harvard University Press.

FIRTH, Raymond (1925): “The Korekore Pa'”. En Journal of Polynesian Society, vol. 34, pp. $1-18$.

FIRTH, Raymond (1936): We the Tikopia: A sociological study of kinship in Primitive Polynesia. London: Allen and Unwin.

FITCH, Nancy (1997): "History after the web: Teaching with Hypermedia". En The History Teacher, vol. 30, 4, pp. 427-441.

Flores, Leonardo (2013): "Digital Textuality and its Behaviors". En On Intermedial Aesthetics and World Literatures. En Journal of Comparative Literature and Aesthetics. (ed.) López-Varela, A. pp. 123-139.

GARris, Rosemary, Ahlers, Robert y Driskell, James E. (2002): “Games, motivation, and learning: A research and practice model". En Simulation \& Gaming, vol. 33, 4, pp. 441-467.

Grishakova, Marina (2004): "Vision and Word: The Seat of the Semiotic Confl ict (H. James, V. Nabokov, A. Hitchcock).” In: Grishakova M., Lehtimäki M.: Intertextuality and Intersemiosis. Tartu: Tartu University Press, 115-133.

Grishakova, Marina (2006).:The Models of Space, Time and Vision in V. Nabokov's Fiction: Narrative Strategies and Cultural Frames. Tartu Semiotics Library 5. Tartu: Tartu University Press.

Grishakova, Marina. (2010): "Intermedial Metarepresentations" in Marina Grishakova \& Marie Laure Ryan. Berlin-New York: De Gruyter, pp. 312-331.

GRISHAKOVA, Marina y RYAN, Marie-Laure (2010): Intermediality and Storytelling. Berlin and New York: De Gruyter.

HALLIDAY, M.A.K. (1973): Explorations in the Functions of Language. Londres: Edward Arnold.

HALliDAY, M.A.K. (1975): Learning how to Mean. Londres: Edward Arnold.

HALlidAY, M.A.K. (1985): "Systemic Background". En Systemic Perspectives on Discourse: Selected Theoretical Papers from the Ninth International Systemic Workshop. Volume 1. (eds.) Benson, J.D.; W.S. Greaves. Norwood, New Jersey: Ablex Publishing Corporation, pp. 91-116.

LÓPEZ-VARELA, Asunción (2006): "Virtual Trips" 6.87.6.2.6 En 6.87.6 Comparative literature in the age of global change. (eds.) Franco Carvalhal T.; Romero, D.;también en 6.87 The role of comparative literature in the sharing of knowledge and in the preservation of cultural diversity. Social Sciences and Humanities. Encyclopedia of Life Support Systems (EOLSS), UNESCO, Eolss Publishers, Oxford, UK.

LÓPEZ-VARELA, Asunción (2011): "Multimodal Metaphor and Intersubjective Experiences: the importance of eye-contact in Davison's graphic novel 'The Spiral Cage' and in Annie Abrahams Net-Project 'On Collaboration'”. En Lavori del Convegno Palazzo degli 
Artista Italiani. (eds.) Masucci, L.; Di Rosario, G. Napoli: Oficina di Letterature Electrónica: 307-324.

LÓPEZ-VAREla, Asunción. "Intermedial Cognitive Semiotics: some examples of multimodal cueing in virtual environments." Annual Review of Cognitive Linguistics. Amsterdam-Philadelphia: John Benjamins, forthcoming 2013

Malinowski, Bronislaw (1973 / 1944): A Scientific Theory of Culture. North Carolina: University Press.

MaLinowski, Bronislaw (1965 / 1945): The Dynamics of Culture Change. London: Yale University Press.

ManOvich, Lev (2002): The Language of New Media. Cambridge: MIT press.

NACK, Frank (sin fecha): Semiotics in Media. ISLA-UvA. <ssms10.project.cwi.nl/presentations/nack/SSMS-Nack.pdf>.

PAtrunjel, Ioan Fabio (2013): "Ut poesis video ludus: On the possibilities of remediating classic literature into video-games." En Journal of Comparative Literature and Aesthetics. (ed.) López-Varela, A. pp. 130-150

Pullinger, Kate y JosePH, Chris (2005): Inanimate Alice. $<$ http://www.inanimatealice.com/>.

Pullinger, Kate, Joseph, Chris y Schemat, Stefan (2004): The Breathing Wall. <www.thebreathingwall.com>.

WOLF, Werner (2003): "Narrative and Narrativity: A Narratological Reconceptualization and Its Applicability to the Visual Arts". Word \& Image, vol. 19, pp. 180-97.

Wolf, Werner (2005): "Intermediality". The Routledge Encyclopedia of Narrative Theory. (ed.) Herman, D.; Jahn, M.; Ryan, M.L. London: Routledge: 252-56.

Wolf, Werner (2011): "(Inter)mediality and the Study of Literature". En New Perspectives on Material Culture and Intermedial Practice. (ed.) Tötösy de Zepetnek, S.; LópezVarela Azcárate, A.; Saussy, H.; Mieszkowski, J. CLCWeb: Comparative Literature and Culture, vol. 13, 3, Purdue University Press <http://docs.lib.purdue.edu/ clcweb/vol13/iss3/>

NOTA: Las imágenes de este artículo pertenecen al primer episodio de la novela que aquí se ha analizado (Inanimate Alice $<$ http://www.inanimatealice.com/ $>$ ) y se pueden encontrar en: $<\mathrm{http}$ //www.inanimatealice.com/episode1 $>$. 


\begin{abstract}
RESUMEN
Las nuevas formas de relacionarse del ser humano con el entorno en el que vive están cada vez más condicionadas por el uso que este hace de las nuevas tecnologías para adquirir y transmitir conocimiento. En este artículo se analiza el nivel de participación activa del usuario en una de las primeras novelas digitales que se utilizaron para la educación a nivel mundial: Inanimate Alice $<$ http://www.inanimatealice.com/>. Esta obra de literatura digital posee elementos que establecen una clara relación con el contexto en el que se usa principalmente (las aulas). Dicha novela es una obra transmediática; es decir, combina diversas plataformas de comunicación al ser una mezcla de varios géneros artísticos: es una novela en formato digital, pero incluye juegos de PC. Inanimate Alice presenta una historia sin narradora visible en las imágenes y con pocas posibilidades de interacción real con la novela-juego. Por ello, este estudio sigue un análisis socio-semiótico de los elementos hipermedia de esta novela digital con el fin de proponer posibles mejoras en el uso de su potencial interactivo e interpersonal.
\end{abstract}

Palabras clave: narrativa transmediática, Inanimate Alice, novela hipermedia, metaficción, material pedagógico digital.

\title{
Transmedia narratives in digital enviroments: Inanimate Alice as a hyperme- dia novel and its educational purposes
}

\begin{abstract}
The new means of interacting with our environment are more conditioned every day due to the spread use of new technologies as a source of knowledge acquisition and transmission. This article analyzes the level of participant-engagement in one of the first digital novels used for pedagogical purposes worldwide: Inanimate Alice $<\mathrm{http} / / \mathrm{www}$.inanimatealice.com/ $>$. This work of digital literature contains a direct reference that establishes a connection to the outer educational environment where it is used. This novel is also a transmedia work as it combines various communication platforms and mixes different artistic genres: it is a digital novel but also a PC game. Inanimate Alice presents a story with an invisible narrator in the images and with very few possibilities of actual manipulation of the novelgame. Therefore, this study follows a socio-semiotic approach of the hypermedia elements of this novel with the purpose of suggesting possible modifications and thus, enhance the interactive and interpersonal engagement of the series.
\end{abstract}

Keywords: transmedia narrative, Inanimate Alice, hypermedia novel, metafiction, digital pedagogic resource. 